\title{
A path through the forest
}

\section{Nerve Endings: The Discovery of the Synapse \\ by Richard Rapport \\ Norton: 2005. 224 pp. $\$ 23.95$}

\section{Jeffry S. Isaacson}

It is not often that one can pinpoint a paradigm-shifting moment of discovery that transforms a scientific discipline, but in the 1800 s, one such moment erupted from a makeshift laboratory in the kitchen of a young Spanish professor. Using not much more than a simple light microscope, pen and paper, and specimens of brain tissue, Santiago Ramón y Cajal (1852-1934) formulated revolutionary concepts that ignited the field of neuroscience.

Nerve Endings, a book from neurosurgeon Richard Rapport, recounts Cajal's life and times. The book also sheds light on Italian histologist Camillo Golgi (1843-1926), whose own kitchen experiments led to the tissuestaining method Cajal used to great effect. But even though both men's accomplishments are intertwined, and led to their joint winning of the Nobel prize in 1906, Cajal and Golgi were scientific rivals with opposing views on the nature of the brain.

Early microscopic studies hinted that the nervous system was made of individual cells (neurons), with numerous protrusions (dendrites) and single, thin emanations (axons). It was another matter to imagine how neurons were organized to convey information.

A popular view in the nineteenth century was that neurons were continuous with one

\section{NEW IN PAPERBACK}

\section{Linnaeus' Philosphia Botanica}

translated by Stephen Freer

(Oxford University Press 635 , \$89.50)

The first full English translation since 1775 of this

classic book summarizing Linnaeus' work on the classification and taxonomy of plants

\section{Uncertain Science ... Uncertain World \\ By Henry Pollack (Cambridge University Press $\notin 12.99$, \$19.99)}

\section{Human-Built World: How to Think About Technology and Culture}

by Thomas P. Hughes (University of Chicago Press, $\$ 13, \notin 9.50$ )

"A virtuoso overview of the various relationships between technology, commerce, society, art and the military." Graham Farmelo Nature 429, 348 (2004).

\section{Subtle is the Lord}

By Abraham Pais (Oxford University Press $\notin 17.99, \$ 22)$

A new edition, with a foreword by Roger Penrose, of this masterfly biography of Albert Einstein. another and formed one gigantic network. This 'reticular theory' seemed quite reasonable as it was an ideal way for information such as sensory input and motor output to flow through the nervous system in both directions. But inefficient techniques for fixing and staining tissue plagued the study of brain microstructure. Typical procedures labelled virtually all neurons and fibres, revealing the forest, but hiding the individual trees, leaves and roots in the thicket.

Golgi, a reserved figure, overcame this dilemma by developing an almost alchemical process based on soaking brain pieces in potassium dichromate and silver nitrate. The result was striking - only a tiny fraction of neurons were impregnated with a dark silver precipitate, making it possible to follow the outline of a single neuron and its tiniest processes. Why this method, which Golgi named the black reaction, labels neurons with such exquisite randomness remains unknown.

Golgi made important observations with his new technique, including that single axons give rise to numerous branches (collaterals). The fine meshwork of axon collaterals represented to Golgi the reticular elements that linked neurons, whereas dendrites played merely a nutritive role.

Much is known about Cajal's life from his eloquent autobiographical writing. His Recollections of My Life (MIT, 1989) should be required reading for any scientist and Rapport draws heavily from it. The son of a small town doctor, Cajal was a mediocre student, obsessed with art, bodybuilding(!) and chess. His compulsive mind became intrigued with deciphering the workings of the brain. Working alone with few resources and only books to guide him, Cajal's neuroscience was done with a passion and fury unrivalled to this day. To him, "an exact knowledge of the structure of the brain was of supreme interest for the building up of a rational psychology. To know the brain ... is equivalent to ascertaining the material course of thought and will."

In 1887, Cajal was introduced to the Golgi staining method and immediately grasped its power. Whereas most neuroanatomists studied adult human brains, Cajal focused on embryonic tissue and the more compact brains of mice and birds. Gazing into his microscope, Cajal conjured "the new truth": axons ended and formed contacts (later termed synapses by Charles Sherrington) very close to the dendrites and cell bodies of other neurons. To Cajal, the reticular theory was clearly wrong and the 'neuron doctrine' was set to take its place. He further proposed the law of 'dynamic polarization' which stated that neurons received information at their dendrites and cell bodies and relayed nerve impulses through their axons.

Cajal saw that by studying the relationship between axons and dendrites he could infer in what direction information travelled across neural circuits. His meticulous drawings of brain circuits - works of science and art are filled with playful arrows showing the direction of information flow. Frustrated by the slow pace of publishing, in 1888 he created his own journal to showcase his findings. When that failed to make an impact, the following year Cajal travelled to Berlin to demonstrate his slides at a meeting of leading anatomists. Fascination over Cajal's preparations led to the rapid confirmation of his conclusions. Despite the quick acceptance of Cajal's neuron doctrine, Golgi stubbornly defended his ideas on reticular theory. It is ironic that the two met for the first time in Stockholm to receive their prizes; Golgi's speech was an attack on neuron theory, Cajal followed with a tactful defense.

As a synaptic physiologist a century later, I find it astonishing that Cajal's simple observa- 
tions led him to infer not only that synaptic contacts existed, but also that the unseen synaptic gaps were the basis of neurotransmission. With uncanny accuracy, he foretold today's hottest research: Cajal envisioned that tiny dendritic protuberances (spines) were important postsynaptic elements and that learning and memory might reflect the growth of new contacts. Rapport does well in making
Cajal accessible to non-neuroscientists. And for those of us who still ponder his drawings to guide us through the tangled forest, Rapport reminds us how lucky we are to have Cajal as our guide and companion.

Jeffry S. Isaacson is in the Department of Neuroscience, University of California, San Diego School of Medicine, La Jolla, California 92093-0608, USA.

\section{An ill-defined idea?}

\section{Lovers and Livers: Disease Concepts in History by Jacalyn Duffin \\ University of Toronto Press: 2005. 240 pp. $\$ 55, £ 35$ (hbk); \$27.50, £20 (pbk)}

\section{Andrew Scull}

Jacalyn Duffin's brief but beguiling book (it contains only 127 pages of text, the rest being consumed by notes and bibliography) is a revised version of the Joanne Goodman lectures, which she delivered at the University of Western Ontario in London, Canada, in 2002. Judging by the sprightliness of her prose, she must have provided an entertaining time for her audience. Along the way, her listeners will have encountered a clever series of arguments for viewing diseases as ideas, and a sometimes passionate dissection of disease and illness, doctor and patient, culture and pathology. At her best, Duffin creates a genuine sense of excitement and engagement with her materials, and these qualities are nowhere more evident than in her concluding chapter on livers (diseases thereof), where she draws fruitfully on her own clinical experience as a haematologist.

The notion that diseases may be thought of as "ideas influenced by the tastes and preoccupations of society" is likely at first to raise hackles in some quarters. Not another postmodernist rant, some will sigh, and sure enough, on the very first page there is a reference to the archfiend Michel Foucault. Not to worry, Duffin is not in the business of denying biological realities. Her point is far more clever and subtle, revolving around a distinction that she is scarcely the first to draw between disease and illness. This is, she concedes, a linguistic convention that will never be observed at the level of everyday speech, but making it here allows us to talk intelligently about two very different phenomena. Illness "applies to the subjective aspects of suffering, the problem experienced by the individual patients" and changes very slowly, if at all, over time; disease, in contrast, refers to "our ideas about that illness", ideas that not only describe symptoms and sufferers, but also incorporate an explanation or a theory about the illness. And diseases often change and proliferate as we recognize and add entities to the list of ailments that afflict the human race. It is this process of medicalization and demedicalization that Duffin's substantive chapters seek to illuminate.

Illnesses - that is, the symptoms experienced and reported by patients - often loom large in the making of a disease concept. Indeed, Duffin contends, "During early modern times, one could not be sick without feeling sick," and even today there are diseases still constructed solely on the basis of symptoms. The 'mental illnesses' that fill the pages of the American Psychiatric Association's Diagnostic and Statistical Manual of Mental Disorders are the most numerous, although scarcely the only,

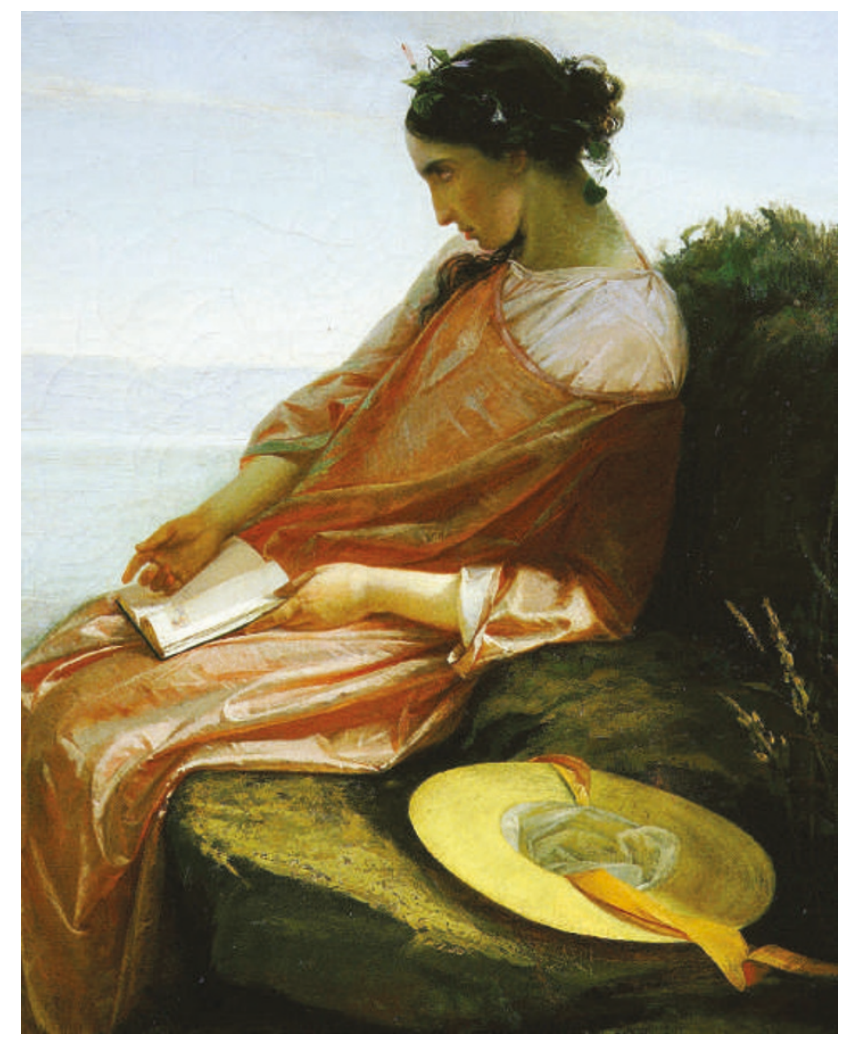

Call a doctor: when diseases were defined by symptoms alone, lovesickness was a clinically respectable diagnosis. examples of the phenomenon. In the modern age, however, patients no longer have the final say on whether they are sick, as modern medicine tends to rely on the signs its techniques and technology can detect - it can even spot hypertension or latent cases of hepatitis $\mathrm{C}$ in asymptomatic people. Alternatively, unable to detect the biological underpinnings of conditions such as chronic fatigue syndrome, the profession uses its cultural authority to cast doubt on the reality of the complaint.

Love has symptoms too, for it has profound physical and psychological effects. Duffin points out that in an era of symptom-based medicine, 'lovesickness' emerged as a clinically respectable disease characterized by such symptoms as anorexia, insomnia and melancholy. It turns out to have an ancient pedigree and lingered in the repertoire of diseases until remarkably recently. Duffin even argues that love "still carries disease overtones in the medical and cultural psyche" today, something she attributes to the fact that it threatens to bring the "loss of control".

I found this portion of the book only intermittently compelling and occasionally selfindulgent. By contrast, Duffin's final chapter on the rise of hepatitis C fizzes with information and ideas that draw the reader into her argument. No one who reads this book will ever again think there is a 'routine' blood transfusion, for example, the hidden perils of this often life-saving procedure being starkly laid bare. More broadly, Duffin's examination of the proliferating array of hepatic diseases leads one to reflect upon a series of ironies surrounding the diagnosis and treatment of disease in the modern era, and to confront the continuing intrusion of moral values into the supposedly value-free realm of medicine.

Consider, for example, the construction of 'guilty' and 'innocent' victims of AIDS and hepatitis C; or the legal and ethical morass that surrounds the question of whether those infected by the blood supply should be financially compensated for their suffering, and by whom; or the complicated and to some degree perverse consequences for individual patients of the discovery that they have a symptomless, untreatable disease that may or may not lead to debility and death at some unknowable time in the future. Life lived beneath the sword of Damocles acquires a whole new meaning, and not one that most of us would welcome. Although as Duffin would be the first to point out, in reality we all exist in such a state anyway, and contrive to hide this painful truth from ourselves at all costs. Andrew Scull is in the Department of Sociology, University of California, San Diego, 9500 Gilman Drive, La Jolla, California 92093-0533, USA. 